\title{
Hubungan Antara Minat Anak Mengikuti Pembelajaran Berbasis Lingkungan Alam dengan Kecerdasan Naturalis Anak Usia Dini
}

\author{
Daniah Afandi \\ Pendidikan Islam Anak Usia Dini, Universitas Islam Negeri Sunan Gunung Djati Bandung \\ Jalan Soekarno Hatta Kel. Cimencrang, Gedebage Kota Bandung, Jawa Barat, Indonesia \\ Email: Daniahafandinew97@gmail.com
}

Naskah diterima: 17 September 2020, direvisi: 22 September 2020, diterbitkan: 23 September 2020

\begin{abstract}
Abstrak
Penelitian ini bertujuan untuk mengetahui realitas hubungan antara minat anak mengikuti pembelajaran berbasis lingkungan alam dengan kecerdasan naturalis anak usia dini di kelas B1 RA Golden Rabbani Kabupaten Bandung. Penelitian menggunakan pendekatan kuantitatif. Jenis penelitian adalah penelitian korelasional. Subjek penelitian yaitu siswa kelompok B1. Teknik pengumpulan data melalui observasi, wawancara, dokumentasi dan unjuk kerja. Teknik analisis data dilakukan secara deskriptif analitik dengan rumus korelasi Rank Spearman. Hasil penelitian menunjukkan bahwa realitas minat anak mengikuti pembelajaran berbasis lingkungan alam berkategori baik ditunjukkan dengan nilai rata-rata sebesar 75. Realitas kecerdasan naturalis anak usia dini berkategori baik ditunjukkan dengan nilai rata-rata sebesar 78. Realitas hubungan antara minat anak mengikuti pembelajaran berbasis lingkungan alam dengan kecerdasan naturalis anak usia dini menghasilkan harga koefisien korelasi sebesar 0,560 artinya berkategori cukup tinggi. Selain itu, hasil uji hipotesis menunjukkan bahwa $t_{\text {hitung }} 2,814$ lebih besar dari $t_{\text {tabel }}$ 2,228 artinya $\mathrm{Ha}$ diterima dan Ho ditolak, dengan kata lain terdapat hubungan positif yang signifikan antara minat anak mengikuti pembelajaran berbasis lingkungan alam dengan kecerdasan naturalis anak usia dini di Kelompok B1 RA Golden Rabbani Kabupaten Bandung.
\end{abstract}

Kata kunci: kecerdasan naturalis, minat anak, pembelajaran berbasis lingkungan alam.

\begin{abstract}
This study aims to determine the reality of the relationship between children's interest in learning based on natural environment and naturalist intelligence of early childhood in class B1 RA Golden Rabbani, Bandung Regency. Research uses a quantitative approach. This type of research is correlational research.
\end{abstract}


The research subjects were students in group B1. Data collection techniques through observation, interviews, documentation and performance. The data analysis technique was done analytically using the Spearman Rank correlation formula. The results showed that the reality of children's interest in learning based on the natural environment categorized well indicated by an average value of 75 . The reality of naturalist intelligence of early childhood categorized good indicated by an average value of 78 . The reality of the relationship between children's interest in learning based on the natural environment with early childhood naturalist intelligence produces a correlation coefficient of 0.560 means that the category is quite high. In addition, the results of the hypothesis test show that t count 2,814 is greater than ttable 2,228 meaning $\mathrm{Ha}$ is accepted and Ho is rejected, in other words there is a significant positive relationship between children's interest in learning based on natural environment with naturalist intelligence of early childhood in Group B1 RA Golden Rabbani Bandung district.

Keywords: naturalist intelligence, children's interests, natural environment-based learning.

\section{Pendahuluan}

Pendidikan Anak Usia Dini (PAUD) sebagai suatu bentuk wahana pendidikan yang fundamental dalam proses pertumbuhan dan perkembangan serta pembentukan karakter anak. Pendidikan Anak Usia Dini diselenggarakan dengan memberikan keteladanan, membangun kemampuan, dan mengembangkan kreativitas peserta didik dalam proses pembelajaran. Proses kreatif dan inovatif dilakukan melalui kegiatan yang menarik, membangkitkan rasa ingin tahu, memotivasi anak untuk berpikir kritis, dan membangun minat anak (Umar, 2010: 27).

Menurut Djamarah (2002: 132) minat adalah kesadaran seseorang bahwa suatu objek, suatu soal atau situasi mengandung sangkut paut dengan dirinya. Minat seseorang terhadapsuatu obyek akan lebih kelihatan apabila obyek sasaran berkaitan dengan keinginan dan kebutuhan seseorang yang bersangkutan. Minat anak dalam mengikuti pembelajaran berbasis lingkungan alam khususnya sangat berkaitan dengan apa yang dibutuhkan dan diinginkan oleh anak di alam luar secara nyata.

Pembelajaran pada anak usia dini merupakan proses eksplorasi anak melalui bermain dan kegiatan observasi lainnya. Isjoni (2010:99) berpendapat bahwa apa yang dipelajari anak itu adalah hal-hal yang nyata dan konkrit serta berkaitan langsung dengan anak maka kegiatan pembelajaran yang diberikan harus menarik perhatian anak dan menyenangkan 
bagi anak serta dapat menimbulkan minat anak sehingga mereka mampu untuk berpikir logis, kritis, memberikan alasan dengan cara memecahkan masalah serta menemukan hubungan sebab-akibat, mengklasifikasikan benda lalu menunjukkan aktivitas yang bersifat eksploratif dan menyelidik. Pembelajaran pada jenjang anak usia dini memiliki beberapa macam salah satunya ada yang disebut dengan pembelajaran berbasis lingkungan alam.

Lingkungan alam menurut Zaman (2008: 104) adalah salah satu fasilitas yang dapat kita gunakan untuk pengajaran di lingkungan PAUD. Dengan fasilitas alam ini, akan membantu anak dan pendidik lebih dekat dengan media yang diajarkan dan yang dipelajari sehingga lebih mudah untuk dipahami dan lebih mendorong anak untuk menemukan sendiri tentang konsep yang dipelajari dalam kehidupan sehari-hari. Melalui bentuk pengajaran ini akan tumbuh keaktifan anak dalam mengamati, menyelediki serta mempelajari lingkungan. Kondisi lingkungan yang sesungguhnya juga akan menarik perhatian spontan anak serta menstimulus kecerdasan yang ada pada diri anak salah satunya kecerdasan naturalis.

Menurut Gardner (2013: 194) Kecerdasan naturalis adalah keahlian mengenali dan mengategorikan spesies yaitu flora dan fauna di lingkungan sekitar, mengenali keberadaan spesies, memetakan hubungan antar spesies. Kecerdasan ini juga meliputi kepekaan pada fenomena alam lainnya (misalnya: formasi awan dan gunung-gunung), dan bagi mereka yang dibesarkan di lingkungan perkotaan, kemampuan membedakan benda tak hidup, seperti mobil, sepatu karet, sampul CD, dan lain-lain. Individu yang memiliki kecerdasan naturalis yang tinggi akan mempunyai minat dan kecintaan yang tinggi terhadap tumbuhan, binatang dan alam semesta.

Berdasarkan pada pengamatan kelas B1 RA Golden Rabbani Kabupaten Bandung, peneliti menemukan adanya fakta di lapangan bahwa masih ada anak yang kurang dalam kepekaan dan sensitivitas terhadap lingkungan sekitar. Seperti yang telah dilakukan di RA Golden Rabbani Kabupaten Bandung dalam pembelajaran berbasis lingkungan alam anak diajak untuk berinteraksi dengan hewan dan tumbuhan serta benda-benda yang ada di lingkungan. Namun masih ada beberapa anak yang belum terangsang dalam kepekaan terhadap benda-benda yang ada di sekitar terutama ketika guru memberikan perintah untuk memanfaatkan benda-benda dan hanya sekedar menunjukkan benda-benda pun anak masih harus dibimbing, di samping itu ada juga sebagian anak yang mudah untuk diarahkan dan sudah memiliki kepekaan terhadap lingkungan alam. 
Berdasarkan pemaparan di atas, maka peneliti tertarik melakukan penelitian yang berjudul "Hubungan Antara Minat Anak Mengikuti Pembelajaran Berbasis Lingkungan Alam Dengan Kecerdasan Naturalis Anak Usia Dini”. Adapun tujuan dari penelitian ini adalah untuk mengetahui realitas hubungan antara minat anak mengikuti pembelajaran berbasis lingkungan alam dengan kecerdasan naturalis anak usia dini di Kelas B1.

\section{Metodologi}

Penelitian ini menggunakan pendekatan kuantitatif. Menurut Arikunto (2013: 12) menyebutkan bahwa penelitian kuantitatif adalah pendekatan penelitian yang banyak dituntut menggunakan angka, mulai dari pengumpulan data, penafsiran terhadap data tersebut, serta penampilan hasilnya. Metode penelitian yang digunakan yaitu penelitian korelasi. Penelitian korelasi melibatkan pengumpulan data yang berguna untuk menentukan ada atau tidaknya hubungan antara dua variabel atau lebih.

Jenis data yang digunakan dalam penelitian ini adalah data kuantitatif dan kualitatif. Menurut Mahmud (2011: 146) data kuantitatif digunakan untuk memperoleh ketetapan atau lebih mendekati angka. Data bersumber dari hasil observasi minat anak mengikuti pembelajaran berbasis lingkungan alam dan kecerdasan naturalis anak usia dini. Sedangkan data kualitatif bersumber dari hasil observasi, unjuk kerja, wawancara serta dokumentasi. Sumber penelitian menurut Mahmud (2011: 147) terbagi menjadi dua macam yaitu sumber primer dan sumber sekunder. Sumber primer, yaitu anak kelas B1 RA Golden Rabbani Kabupaten Bandung dengan jumlah 12 anak. Sumber sekunder, yaitu kondisi objektif sekolah.

Data dikumpulkan melalui observasi, wawancara dan dokumentasi. Observasi menurut Dimyati (2006: 54) adalah metode pengumpulan data penelitian dengan melalui pengamatan terhadap objek yang diteliti. Observasi ini dilakukan untuk memperoleh data tentang minat anak mengikuti pembelajaran berbasis lingkungan alam dan unjuk kerja dilakukan untuk memperoleh data tentang kecerdasan naturalis anak usia dini dengan menggunakan lembar observasi dan lembar unjuk kerja. 
Analisis data dalam penelitian ini sebagai berikut.

1. Deskripsi analisis parsial

Setelah diketahui nilai rata-ratanya, lalu diinterpretasikan ke dalam lima norma skala angka dari 0 sampai 100 sebagai berikut :

Tabel 1. Skala kualifikasi analisis parsial perindikator

\begin{tabular}{ccc}
\hline No & Tingkat Penguasaan & Predikat \\
\hline 1 & $80-100$ & Sangat Baik \\
2 & $70-79$ & Baik \\
3 & $60-69$ & Cukup \\
4 & $50-59$ & Kurang \\
5 & $0-49$ & Kurang Sekali \\
\hline
\end{tabular}

2. Uji normalitas dan uji reliabilitas

3. Analisis Korelasi Variabel X dan Variabel Y

4. Menentukan kriteria pengambilan keputusan atau kriteria uji linieritas

5. Menghitung koefisien korelasi

Jika salah satu dari kedua variabel berdistribusi tidak normal atau regresinya tidak linier, maka rumus yang digunakan yaitu korelasi Rank atau korelasi tata jenjang atau Spearman Rank (rho) dengan rumus:

$$
\rho=1-\frac{6 \sum D^{2}}{N\left(N^{2}-1\right)}
$$

(Sudijono, 2006: 79)

6. Uji Hipotesis

7. Menafsirkan harga koefisien korelasi dengan kriteria sebagai berikut:

Tabel 2. Skala Kualifikasi Hubungan Antara Minat Anak Mengikuti Pembelajaran Berbasis Lingkungan Alam dengan Kecerdasan Naturalis Anak Usia Dini

\begin{tabular}{ccc}
\hline No & Tingkat Penguasaan & Predikat \\
\hline 1 & $0,800-1,000$ & Sangat Kuat/Sangat Tinggi \\
2 & $0,600-0,799$ & Kuat/Tinggi \\
3 & $0,400-0,599$ & Cukup Tinggi/Sedang \\
4 & $0,200-0,399$ & Rendah \\
5 & $0,000-0,199$ & Sangat Rendah \\
\hline \multicolumn{2}{c}{ Sumber: Riduwan (2015: 138$)$}
\end{tabular}




\section{Hasil dan Diskusi}

Penelitian ini berusaha untuk menjawab permasalahan penelitian tentang minat anak mengikuti pembelajaran berbasis lingkungan alam hubungannya dengan kecerdasan naturalis anak usia dini di kelas B1 RA Golden Rabbani Kabupaten Bandung. Berdasarkan hasil pengolahan data yang terkumpul dengan teknik pengambilan data observasi dan unjuk kerja diperoleh sebagai berikut.

1. Realitas Minat Anak Mengikuti Pembelajaran Berbasis Lingkungan Alam di Kelas B1

RA Golden Rabbani Kabupaten Bandung

Berdasarkan perhitungan yang telah dilakukan, hasil pengujian normalitas data minat anak mengikuti pembelajaran berbasis lingkungan alam di kelas B1 RA Golden Rabbani Kabupaten Bandung didapatkan hasil bahwa $X_{\text {hitung }}^{2}<X_{\text {tabel }}^{2}$ dengan $(\mathrm{db})=2$ dan taraf signifikan 5\% maka data tersebut berdistribusi normal, yang ditunjukkan dengan perolehan nilai $X_{\text {hitung }}^{2}(5,180)$ dan $X_{\text {tabel }}^{2}(5,990)$ sehingga $X_{\text {hitung }}^{2}$ lebih kecil dari $X^{2}{ }_{\text {tabel }}$.

Minat anak mengikuti pembelajaran berbasis lingkungan alam di kelas B1 RA Golden Rabbani Kabupaten Bandung menurut peneliti sudah baik, karena dilihat dari hasil analisis observasi minat anak mengikuti pembelajaran berbasis lingkungan alam berada pada kategori baik yaitu dengan ditunjukkan oleh nilai rata-rata 75 dan berada pada interval $70-$ 79.

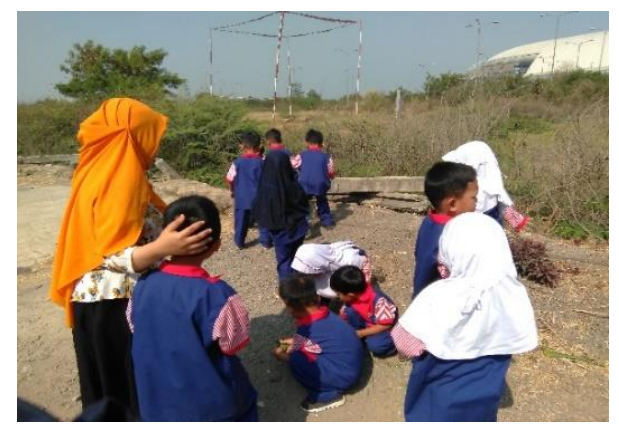

Gambar 1. Anak Mencari Benda di Sekitar

Hal ini didukung oleh pendapat Karjiyadi (2012:112) mengatakan bahwa "Pembelajaran berbasis lingkungan mengarah pada pembelajaran yang memanfaatkan lingkungan sebagai sumber belajarnya. Lingkungan dapat diformat maupun digunakan sebagai sumber belajar. Dalam hal ini, guru dapat mengaitkan antara materi yang diajarkan 
dengan situasi dunia nyata anak sehingga dapat mendorong anak membuat hubungan antara pengetahuan yang dimilikinya dengan penerapannya dalam kehidupan sehari-hari.

2. Realitas Kecerdasan Naturalis Anak Usia Dini di Kelas B1 RA Golden Rabbani Kabupaten Bandung

Berdasarkan perhitungan yang telah dilakukan, hasil pengujian normalitas data kecerdasan naturalis anak usia dini di kelas B1 RA Golden Rabbani Kabupaten Bandung didapatkan hasil bahwa $X_{\text {hitung }}^{2}<X^{2}{ }_{\text {tabel }}$ dengan $(\mathrm{db})=2$ dan taraf signifikan $5 \%$ maka data tersebut berdistribusi normal, yang ditunjukkan dengan perolehan nilai $X_{\text {hitung }}^{2}$ $(5,351)$ dan $X_{\text {tabel }}^{2}(5,990)$ sehingga $X_{\text {hitung }}^{2}$ lebih kecil dari $X_{\text {tabel }}^{2}$.

Kecerdasan naturalis anak usia dini di kelas B1 RA Golden Rabbani Kabupaten Bandung menurut peneliti sudah baik, karena dilihat dari hasil analisis unjuk kerja kecerdasan naturalis anak usia dini berada pada kategori baik yaitu dengan ditunjukkan oleh nilai rata-rata 78 dan berada pada interval 70 - 79. Nilai ini adalah nilai rata-rata pertengahan dari interval 70 - 79, karena banyak indikator yang termasuk pada kualifikasi baik. Namun ada juga indikator yang mencapai nilai sangat baik karena berada pada interval 80 - 100 diantaranya: a) item nomor 7 yaitu anak memisahkan sampah plastik dan sampah daun; b) item nomor 8 yaitu anak bertanya tentang cara menyiram tanaman; c) item nomor 9 yaitu anak menyiram tanaman dengan tepat; dan d) item nomor 12 yaitu anak memilih daun yang layu.

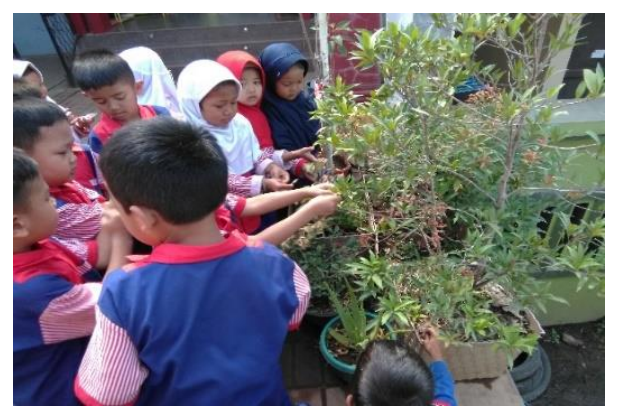

Gambar 2. Anak memisahkan daun yang layu

Hal ini didukung oleh pendapat Musfiroh (2010: 87) bahwa kecerdasan naturalis anak pada usia 4-6 tahun muncul dalam bentuk sudah mulai memiliki rasa kepekaan terhadap lingkungan sekitar, mereka sudah memiliki minat terhadap alam, merawat dan memelihara hewan/tumbuhan, mendokumentasikan melalui gambar, dan mencari informasi melalui bertanya, melihat tayangan, dan membaca. 
3. Realitas Hubungan Antara Minat Anak Mengikuti Pembelajaran Berbasis Lingkungan Alam dengan Kecerdasan Naturalis Anak Usia Dini di Kelas B1 RA Golden Rabbani Kabupaten Bandung

Berdasarkan hasil perhitungan dengan menggunakan Rank Spearman diperoleh harga koefisien korelasi antara minat anak mengikuti pembelajaran berbasis lingkungan alam (Variabel X) hubungannya dengan kecerdasan naturalis anak usia dini (Variabel Y) sebesar 0,560. Angka koefisien korelasi 0,560 berada pada interval 0,400 - 0,599 artinya memiliki hubungan yang cukup tinggi. Selanjutnya hasil uji hipotesis menunjukkan bahwa nilai t_hitung $=2,814$ lebih besar dari t_tabel $=2,228$ dengan $(\mathrm{dk})=10$ pada taraf signifikan 5\%. Artinya terdapat hubungan positif yang signifikan antara minat anak mengikuti pembelajaran berbasis lingkungan alam dengan kecerdasan naturalis anak usia dini di kelas B1 RA Golden Rabbani Kabupaten Bandung.

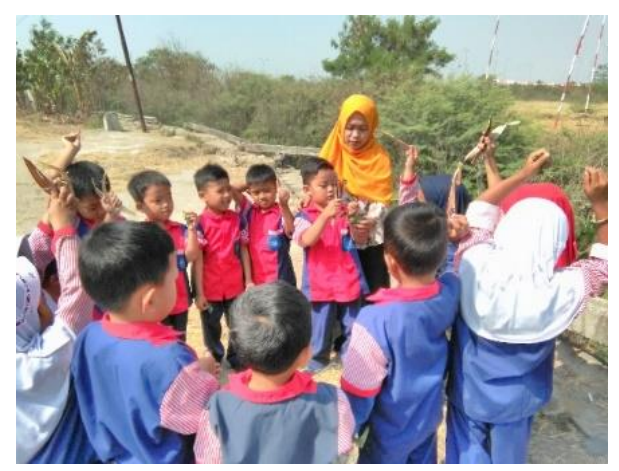

Gambar 3. Anak membedakan daun basah dan kering

Menurut Jan Lighthart dalam teorinya yang disebut teori naturalistik menyebutkan bahwa seseorang yang memiliki rasa partisipasi dan minat terhadap pembelajaran yang berbasis pada alam maka hal itu akan berpengaruh pada kecerdasan naturalis yaitu kepekaan terhadap lingkungan alam. Dalam teorinya menjelaskan bahwa pembelajaran yang melibatkan benda-benda di sekitar lingkungan alam akan lebih menarik minat anak untuk mengembangkan seluruh potensinya terutama dalam ranah kecerdasan naturalis anak karena dengan berinteraksi di lingkungan alam maka anak akan terlatih kepekaan serta sensitivitasnya terhadap sesuatu yang terjadi dan yang berhubungan dengan alam (Gemasastrin, 2008: 56). Hal ini berkaitan dengan pendapat Howard Gardner yang menyatakan bahwa Individu yang memiliki kecerdasan naturalis yang tinggi akan mempunyai minat dan kecintaan yang tinggi terhadap tumbuhan, binatang dan alam semesta, dan ia juga akan cenderung menjaga lingkungan di mana individu itu berada. (Gardner, 2013: 195). 
Hasil penelitian ini juga berkaitan dengan Penelitian terdahulu yang telah dilakukan oleh Etika Lizawati (2016) tentang Hubungan Aktivitas Pembelajaran Berbasis Lingkungan Alam dengan Perkembangan Kemampuan Sains pada Anak Usia 5-6 Tahun di TK Dharma Wanita Sekincau Lampung Barat. Program Studi Pendidikan Guru Anak Usia Dini, Jurusan Ilmu Pendidikan. Fakultas Keguruan dan Ilmu Pendidikan di Universitas Lampung, Bandar Lampung. Hasilnya menunjukkan bahwa pembelajaran berbasis lingkungan alam ada hubungannya dengan perkembangan kemampuan sains pada anak usia dini.

\section{Penutup}

Realitas minat anak mengikuti pembelajaran berbasis lingkungan alam sudah berkategori baik dengan nilai rata-rata 75 . Alangkah lebih baik lagi jika minat anak dalam hal belajar khususnya dalam pembelajaran berbasis lingkungan alam ditanamkan dan dikembangkan sejak dini agar anak terlatih dan siap untuk menghadapi kondisi di lingkungan sekitarnya. Realitas kecerdasan naturalis anak usia dini sudah berkategori baik dengan nilai rata-rata 78. Untuk mendapatkan hasil yang lebih baik lagi maka perlu dikembangkan melalui berbagai jenis pembelajaran agar dapat terlihat sejak dini sehingga mencapai target yang sangat baik. Realitas di lapangan menunjukkan bahwa hubungan antara minat anak mengikuti pembelajaran berbasis lingkungan alam dengan kecerdasan naturalis anak usia dini masih tergolong cukup dengan nilai koefisien korelasi sebesar 0,560, ini menandakan bahwa perlu ada peningkatan yang lebih baik lagi, baik dari segi metode mengajar maupun materi yang harus disampaikan. Bagi peneliti yang akan melakukan penelitian kuantitatif dengan menggunakan metode korelasional, hendaknya merancang instrumen dengan sematang dan sebaik mungkin untuk anak usia dini agar sesuai dengan kebutuhan dan materi yang telah dipelajari oleh anak.

\section{Daftar Pustaka}

Arikunto, S. (2013). Prosedur Penelitian Suatu Pendekatan Praktik. Jakarta: Rineka Cipta.

Dimyati dan Mudjiono. (2006). Belajar dan Pembelajaran. Jakarta: PT. Rineka Cipta.

Djamarah, S. B. (2008). Psikologi Belajar. Jakarta : PT. Rineka Cipta.

Gardner, H. (2013). Multiple Intelligences. Jakarta: Daras Book.

Gemasastrin. (2008). Teori Multiple Intelegence dalam Pendidikan Anak. Bandung: Rineka cipta. 
Isjoni. (2010). Model Pembelajaran Anak Usia Dini. Bandung: Alfabeta.

Karjiyadi. (2012). Pembelajaran Berbasis Lingkungan. Jakarta: Gramedia Pustaka Utama.

Mahmud. (2011). Metodologi Penelitian Pendidikan. Bandung: CV Pustaka Setia.

Musfiroh, T. (2010). Perkembangan Kecerdasan Majemuk. Jakarta: Universitas Terbuka.

Riduwan, E. A. K. (2015). Dasar-Dasar Statistika. Bandung: Alfabeta.

Sudijono, A. (2006). Pengantar Statistik Pendidikan. PT. Raja Grafindi Persada.

Syah, M. (2009). Psikologi Belajar. Jakarta: PT. Raja Grafindo Persada.

Umar, A. (2010). Sukses Menjadi Guru TK-PAUD (Tips, strategi, dan panduan-panduan pengembangan praktisnya). Yogyakarta: Bening.

Zaman. (2008). Pengertian Lingkungan. (online). Diunduh pada 27 Januari 2019, dari http:phierda. Wordpress.com 2012/10/30/pengertian-lingkungan. 